\title{
Future of kidney stone surgery: will we treat small stones with large-sized PCNL and big stones with RIRS?
}

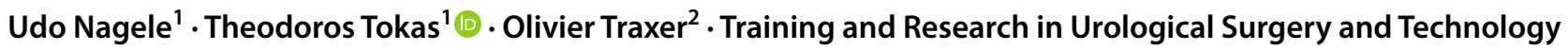 \\ (T.R.U.S.T.)-Group
}

Received: 22 September 2019 / Accepted: 4 October 2019 / Published online: 18 October 2019

○) Springer-Verlag GmbH Germany, part of Springer Nature 2019

Keywords Minimally invasive percutaneous stone treatment $\cdot$ MIP $\cdot$ MIP S $\cdot$ Flexible ureteroscopy $\cdot$ Retrograde intrarenal surgery $\cdot$ RIRS $\cdot$ Endourology $\cdot$ Access $\cdot$ Laser $\cdot$ Residual fragments $\cdot$ Trauma $\cdot$ Low- and high-risk stone former

For many years endourologists are searching for the most efficient and least traumatic stone treatment. More and more miniaturized instruments and innovative stone disintegration tools are continuously expanding our armamentarium [1, 2]. Meanwhile, currently available modern imaging modalities are able to detect more and smaller residual fragments postoperatively. In that way, the average stone-free rates are decreasing dramatically despite our new sophisticated treatment options [3]. Dealing with this dilemma we have to take into consideration that in first-time stone formers complete stone-free status seems to be of uttermost importance since even residual fragments smaller than $4 \mathrm{~mm}$ could be responsible for acute symptoms in the future [4-6]. But what are the possibilities to offer the best solution to our patients? Which technologies fit the need for the least traumatic but most efficient procedure in stone surgery?

Accessing almost every part of the kidney is possible with new flexible multiple-use and disposable instruments. Pressure control can be achieved by the use of access sheaths and irrigation/suction devices. New high-frequency and lowpower laser technologies enable us to dust stones of any composition and size in reasonable time and minimum risk. Yet late postoperative radiologic control after 1-3 months

Theodoros Tokas

ttokas@yahoo.com

Udo Nagele

udo.nagele@tirol-kliniken.at

Olivier Traxer

olivier.traxer@aphp.fr

1 Department of Urology and Andrology, General Hospital Hall in Tirol, Milser Str. 10, 6060 Hall in Tirol, Austria

2 Department of Urology, Tenon University Hospital, Marie Curie University, Paris, France is discouraging [3, 7]. A significant number of patients suffer from residual fragments and their consequences, namely renal colic and stone growth $[6,8]$. A number of well-known factors may play a role in postoperative stone clearance, like patient mobility, kidney geometry, and fluid intake [9]. Nevertheless, a straightforward prediction of a stone-free status cannot always be made preoperatively.

Recent knowledge about different tract dilation methods might relativize the theory of size-related bleeding complications in PCNL [10]. The most effective method does avoid residual fragments by achieving stone extraction in one piece. Risk stratification of stone patients in high and low-risk stone formers and its impact on new stone formation might help us to predict the necessity of a stone-free status in low-risk patients [6]. On the other hand, in the case of high-risk stone formers, fragments can be removed in minimum time, leaving eventually dust and plaques behind but reducing an intervention-dependent risk. Taking all these factors into account, we could treat a small stone in a lowrisk stone former with a big access PCNL, harvesting the stone en bloc to reduce future stone formation and at the same time do a flexible approach even in larger stone burden in high-risk stone formers, knowing that these patients suffer from future stones anyway.

Author contributions UN: data collection and management, data analysis, manuscript writing and editing, project development. TT: manuscript editing. OT: manuscript writing and editing, data analysis, project development.

Funding No financial support. 


\section{Compliance with ethical standards}

Conflict of interest No conflicts of interest.

Human and animal rights This letter does not involve human participants and/or animals.

\section{References}

1. Scotland KB, Kroczak T, Pace KT, Chew BH (2017) Stone technology: intracorporeal lithotripters. World J Urol 35(9):13471351. https://doi.org/10.1007/s00345-017-2057-x

2. Huusmann S, Nagele U, Herrmann TR (2017) Miniaturization of percutaneous nephrolithotomy Smaller, but better? Curr Opin Urol 27(2):161-169. https://doi.org/10.1097/mou.0000000000 000375

3. Tokas T, Habicher M, Junker D, Herrmann T, Jessen JP, Knoll T, Nagele U (2017) Uncovering the real outcomes of active renal stone treatment by utilizing non-contrast computer tomography: a systematic review of the current literature. World J Urol 35(6):897-905. https://doi.org/10.1007/s00345-016-1943-y

4. Rebuck DA, Macejko A, Bhalani V, Ramos P, Nadler RB (2011) The natural history of renal stone fragments following ureteroscopy. Urology 77(3):564-568. https://doi.org/10.1016/j.urolo gy.2010.06.056

5. Portis AJ, Laliberte MA, Tatman P, Lendway L, Rosenberg MS, Bretzke CA (2014) Retreatment after percutaneous nephrolithotomy in the computed tomographic era: long-term follow-up. Urology 84(2):279-284. https://doi.org/10.1016/j.urolo gy.2014.02.041

6. Hein S, Miernik A, Wilhelm K, Schlager D, Schoeb DS, Adams F, Vach W, Schoenthaler M (2016) Endoscopically determined stone clearance predicts disease recurrence within 5 years after retrograde intrarenal surgery. J Endourol 30(6):644-649. https:// doi.org/10.1089/end.2016.0101

7. Ghani KR, Wolf JS (2015) What is the stone-free rate following flexible ureteroscopy for kidney stones? Nat Rev Urol 12(5):281288. https://doi.org/10.1038/nrurol.2015.74

8. Osman Y, Harraz AM, El-Nahas AR, Awad B, El-Tabey N, Shebel H, Shoma AM, Eraky I, El-Kenawy M (2013) Clinically insignificant residual fragments: an acceptable term in the computed tomography era? Urology 81(4):723-726. https://doi. org/10.1016/j.urology.2013.01.011

9. Ito H, Kuroda S, Kawahara T, Makiyama K, Yao M, Matsuzaki J (2015) Preoperative factors predicting spontaneous clearance of residual stone fragments after flexible ureteroscopy. Int J Urol 22(4):372-377. https://doi.org/10.1111/iju.12690

10. Dehong C, Liangren L, Huawei L, Qiang W (2013) A comparison among four tract dilation methods of percutaneous nephrolithotomy: a systematic review and meta-analysis. Urolithiasis 41(6):523-530. https://doi.org/10.1007/s00240-013-0598-z

Publisher's Note Springer Nature remains neutral with regard to jurisdictional claims in published maps and institutional affiliations. 